\title{
Research on Innovation and Entrepreneurship Teaching System of Engineering Graphics Course Group
}

\author{
Yuhuang Zheng ${ }^{1,2}$ \\ 1. Department of Physics and Information Engineering \\ Guangdong University of Education \\ ${ }^{2}$ Guangdong Province Key Laboratory of Precision Equipment and Manufacturing Technology \\ Guangzhou, China \\ zhyhaa@126.com
}

\begin{abstract}
This paper studies the teaching content of engineering drawing course group and the teaching system facing innovation and entrepreneurship. Engineering drawing course group takes engineering drawing as the core and theoretical foundation, and computer aided analys is and manufacture is on the basis of engineering drawing and further study threedimensional modeling. Metalworking practice is a practical engineering practice. The teaching content of this course group is closely related to the needs of enterprises. After completing the course group's teaching, the students will improve their technological level of innovation and entreprene urship.
\end{abstract}

Keywords—engineering drawing; computer aided analysis; metalworking practice

\section{INTRODUCTION}

With the development of social economy, curriculum reform is increasingly required to consider the comprehensiveness and integrity of students' physical and mental development. One of the main tasks of the course construction of electronic information engineering is to solve the problem of how to cultivate the students' quality and improve the practical ability in the course teaching. The students' knowledge, skills, practice ability, innovative spirit and innovation ability, and the cultivation of quality will be given full consideration and high attention in the course construction process. The construction of the curriculum conforms to this requirement. The engineering graphics course group consists of three courses: engineering drawing, computer aided analysis and manufacturing, metalworking practice[1-2].

\section{TEACHING SYSTEM OF ENGINEERING DRAWING CouRSE} GROUP

The engineering drawing of electronic information engineering, because of less learning hours, has reduced the difficulty of teaching content in the course of teaching, and still can meet the needs of the major. As a practical course, engineering drawing not only needs to cultivate logical thinking ability, but also needs to cultivate a strong image thinking ability. The experiment on the computer is AutoCAD computer drawing, which is mainly to cultivate the advanced drawing ability of the students, so that students can quickly master the basic functions and operation techniques of AutoCAD in a short time[3-4].

The engineering drawing course is a required technical basic course for engineering majors. It serves the machinery manufacturing, construction, chemical industry, electronic industry, resource and environment and many other industries. Engineering drawing plays an important role in training students' comprehensive qualities such as image thinking, scientific research and innovation ability. The purpose of this course is to cultivate high-quality applied engineering talents with good image thinking and design expression ability. With the development of science, the traditional instillation teaching method can't meet the learning needs of the engineering students. The combination of engineering drawing and computer technology has greatly changed the theory and technology of engineering drawing. Therefore, teaching should also change. Innovation is the only way in the teaching process of engineering graphics. It is necessary to integrate all kinds of innovative projects, innovative competitions and academic activities with the content of classroom teaching, to stimulate the creative power of students and to cultivate the creative craftsmen in accordance with the development of the times. In the process of innovation, students should pay more attention to design details, pay more attention to quality and efficiency, and comply with national standards and regulations[5-6].

Computer aided analysis and manufacturing is an elective course in this major. There are two tasks in this course. (1) computer aided analysis and analysis of the structural and mechanical properties of complex engineering and products, and the optimization of the structure and performance, organically organize the various links of the engineering (production), and make use of computer aided to complete the preparation from production. The activity of the whole process of producing the product, that is, by directly or indirectly connecting the computer with the manufacturing process and production equipment; (2) the planning, management of the manufacturing process, the control and operation of the production equipment by the computer system, the processing of the data required in the process of manufacturing the product, and the control and processing of materials. The flow of blanks 
and parts, etc., testing and testing products. Computer aided analysis and manufacturing is a three-dimensional modeling software course centered on Solidworks. Through learning three-dimensional modeling software, it is not only easy to understand the content of digestive engineering drawing class, but also help students to understand the engineering drawings and assembly drawings, and also provide digital modeling and verification for the students' creative activities design[7-8].

Metalworking practice is a compulsory course for this major. It is a required course for students to understand the machining process, cultivate practical ability and engineering quality. Cultivate students' engineering consciousness, practical ability and innovative spirit, and improve their comprehensive quality. Through metalworking practice, students develop a work style of loving labour and linking theory with practice. Broaden the horizon of knowledge and enhance employment. Metalworking practice takes car workers and fitter as the core teaching content. Through metalworking practice, students are familiar with the general process of mechanical manufacturing, master the main process methods and process processes of metal processing, be familiar with the safe operation and use of various equipment and tools, understand the use of new technology and new techniques in mechanical manufacturing; master the Ability to process simple parts and process analysis; develop students' ability to understand drawings, machining symbols and understand technical conditions.

\section{THE TEACHING REFORM OF ENGINEERING DRAWING COURSE GROUP}

\section{A. Update the Content of the Course}

With the development of the times, the national standard of engineering drawing is constantly being updated, and the connotations of computer-aided analysis and manufacturing are also improving. How to implement the new national standard should be reflected in the improvement of teaching content. In the national standard, the contents of surface roughness and shape tolerance are improved, so these needs to be updated in time and in the course of teaching materials and teaching, to introduce the latest national standards to students, to make students familiar with and to use the new national standard correctly. At the same time, in the supporting textbooks and exercise books, the new GB is used to replace the old GB. Let students learn the latest knowledge of cartography and let students know that engineering drawing is a rigorous course that requires continuous learning and continuous thinking. In order to cultivate students' rigorous learning attitude and design attitude in the usual teaching process.

\section{B. Promote Curriculum Learning by Competition}

While studying engineering drawing course group, the teacher will introduce students to all kinds of innovation competitions, such as Guangzhou university innovation competition, Challenge Cup and so on. These innovation competitions promote students' learning enthusiasm. In addition, the award-winning works in the previous competitions as teaching materials for students to explain, through an intuitive image of the students to enhance the sense of the senses, by learning the design concept of the elder sister, to stimulate the students' interest in learning and innovative consciousness. By giving all kinds of lecture information to students, they will have access to industry experts. When explaining the contest works, the professional design ability is integrated into the teaching of engineering drawing. The contents of engineering drawing are related to the requirements of the design of professional courses, and the theoretical knowledge of engineering drawing, computer drawing and advanced design ideas are integrated into the whole teaching process of engineering drawing so as to improve the students' creative ability. Through the explanation of examples, students are guided to find inspiration in life and find innovative design topics in their lives. Prepare for all kinds of design competitions in advance.

\section{Innovative and Entrepreneurial Projects are Introduced into the Course Teaching}

At present, all kinds of innovation and entrepreneurship projects are attracting more and more attention from students. These projects provide undergraduate opportunities for innovation and entrepreneurship in schools. Through the guidance of teachers, students can independently complete the design, research preparation and project realization of innovative research projects, write research reports, and exchange results. By participating in these projects, students' creativity and entrepreneurial ability can be strengthened. In the course of engineering drawing course group teaching, the students are introduced to the students in the course of innovation and entrepreneurship by introducing all kinds of innovative and entrepreneurial projects to students, to find out the innovative problems in the course of the course and to learn the following courses with the problems. In the course of explanation, we will introduce the former National College Students' innovation projects to the students through an example, and improve their interest in the course of learning and drawing.

\section{CONCLUSION}

Engineering drawing is one of the most important technical basic courses of all majors in engineering colleges, which is a basic technology course with strong theory and practice. The engineering drawing course introduces the basic theories and methods of drawing and reading engineering drawings, as well as the national standards related to mechanical drawing and engineering drawing. This paper puts forward the teaching system of "Engineering Drawing" course group. Through the study of this course group, the students master the basic knowledge of drawing and reading engineering drawings, mastering the mechanical design and analysis techniques, and cultivating the students' conscientious and conscientious spirit and meticulous work style. This course group plays an important role in training students' comprehensive quality. In the last three years, the course group has been opened in the major of electronic information engineering in our department. The teaching plan, organization, evaluation and follow-up courses have been explored in many aspects, and the teaching level and quality improvement have achieved remarkable results. 


\section{ACKNOWLEDGMENT}

This article is one of the stage achievements of the following projects: 2017 Research and practice of new engineering talents training of Electronic Information Engineering Specialty; 2017 the education project of university innovation and entrepreneurship in Guangzhou (No. 2017192201); 2017 Quality project of Guangdong University of Education (No. 2017zdzz01); 2017 Innovation and Entrepreneurship Education Program of Guangdong University of Education; 2016 Guangdong Provincial Key Laboratory of Precision Equipment and Manufacturing Technology project (No. PEM201604).

\section{REFERENCES}

[1] M. Amran, R. Sulaiman and R. Ahmad, "Entities filtering technique for information extraction in engineering drawing files,” J. Fund. Appl. Sci., vol. 9, pp.199-209, Sept. 2017.

[2] A. Singh-Pillay and D.S. Sotsaka, "Engineering graphics and design teachers understanding and teaching of assembly drawing”, EURASIA J. Math., Sci. Tech. Edu., vol.13, pp. 1213-1228, May 2017.

[3] Jr. Hedberg, N. Hartman and P. Rosche, "Identified research directions for using manufacturing knowledge earlier in the product life cycle”, Int. J. Pro. Re., vol.55, pp.819-827, Mar. 2017.

[4] N. Pholdee, S. Bureerat and H. Baek, "Two-stage surrogate assisted differential evolution for optimization of a non-circular drawing sequence”, Int. J. Pre. Eng. Man.,vol. 18, pp.567-573, April 2017.

[5] M. Mohamed, F. Hashim, M. Amini, "Finite element analysis of car hood for impact test by using Solidworks software in automotive application”, J. Fund. Appl. Sci., vol.10, pp. 936-955, Jan. 2018.

[6] V. Babu,M. Majumder, A. Ramprasad, "Involute Tooth Spacing, Gear Profile and 3D Gear development with MATLAB Graphical User Interface and Solidworks”, Int. J. Ind. Eng.,vol. 2, pp.67-75,Mar. 2018.

[7] A.Seixas, "The impact of shift work on burnout syndrome, depression, anxiety and stress: A case study in the metalworking industry", Int. J. Occ. Env. Saf. vol. 2, pp.1-8, Jan. 2018.

[8] E. Shchelkunov, "Parameter for evaluation of the layout arrangement of the metalworking machines with parallel kinematics", J. Mach. Man. Re. vol.46, pp.448-452, May 2017. 